\title{
Post Acceptance Model for Online Teleconsultation services: An Empirical Study in Malaysia
}

Case study

\author{
Abdulaziz Aborujiah \\ Universiti Kuala Lumpur \\ Malaysian Institute of Information Technology (MIIT) \\ 1016, Jalan Sultan Ismail, Bandar Wawasan, 50250, \\ Kuala Lumpur, Malaysia \\ abdulazizsaleh@unikl.edu.my
}

\author{
Rasheed Mohammad Nassr \\ Universiti Kuala Lumpur \\ Malaysian Institute of Information Technology (MIIT) \\ 1016, Jalan Sultan Ismail, Bandar Wawasan, 50250, \\ Kuala Lumpur, Malaysia \\ rasheed@unikl.edu.my
}

\author{
Zalizah Awang Long \\ Universiti Kuala Lumpur \\ Malaysian Institute of Information Technology (MIIT) \\ 1016, Jalan Sultan Ismail, Bandar Wawasan, 50250, \\ Kuala Lumpur, Malaysia \\ zalizah@unikl.edu.my

Mohd Nizam Husen
Universiti Kuala Lumpur
Malaysian Institute of Information Technology (MIIT)
1016, Jalan Sultan Ismail, Bandar Wawasan, 50250,
Kuala Lumpur, Malaysia
mnizam@unikl.edu.my

\author{
Abdulaleem Al- Othmani \\ De montfort university \\ Cyber Technology Institute \\ Gateway House, Leicester LE1 9BH, UK \\ aleem.al-othmani@dmu.ac.uk
}

\begin{abstract}
Most nations across the world are actively pursuing equal access to healthcare services. Teleconsultation technology is a substantial improvement in terms of an effective framework for the provision of healthcare services. However, a lack of understanding of people's willingness towards the use of this technology has been observed. The goal of this study is to investigate the factors affecting the post-acceptance of teleconsultation services in Malaysia. This study developed a theoretical model which involves the combination of the second generation of Unified Theory of Acceptance and Use of Technology (UTAUT2) and Expectation Confirmation Theory (ECT), with the inclusion of several other constructs. An online survey was used to collect data from 154 university students and partial least squares (PLS) approach was used for data analysis. The research findings indicate that confirmation, performance, effort expectancy, usefulness, and satisfaction were the key factors that affect the post-acceptance of teleconsultation services. Furthermore, actual use, ease of use, technology readiness, and facilitating conditions did not impact participants' post intention in the continuous usage of teleconsultation facilities.
\end{abstract}

Keywords: Teleconsultation Technology, UTAUT2, ECT, Post Acceptance model, COVID19, PLS_SEM

\section{INTRODUCTION}

The new Information and Communication Technology (ICT) age have radically transformed human life, econom-ic processes, and culture into a new era of application that makes life easier [1]. The expansion of the Internet has contributed to the popularization of various virtual networks of online services [2] such as online learning and telehealth services. Telehealth services are described as health services that allow patients to receive therapy within their day-to-day life through one or more medical specialists [3]. Researchers have found that telehealth has steadily become the leading ICT ser- vice with an impres-sive impact on conventional health mechanisms [4]. Globally, telehealth programs boost doctors' efficacy, reduce medical costs, and increase access to healthcare [5][6]. They also provide services of medical practitioners consisting of tracking, diagnosis, and care provision over long distances using telecommunications. Previous stud-ies have proposed telehealth as a potential option for treating multiple health conditions including high blood pressure, obesity, diabetes, and cancer [6]. It is crucial to analyze the factors that influence end users' perception of adopting telehealth services [7]. so more studies have explored the key fac- 
tors that motivate users to adopt such applications [1214]. However, despite the huge number of emerging health applications, only a small number of apps (such as Noom Diet, Nike+, and Lose It) have been successful across the entire mHealth market. Although health apps are extremely useful in helping individuals to manage their health effectively, their usage often lasts a short while. This indicates a lack of under-standing of people's actions after installing health apps on their smartphones [3]. The aim of this study is, therefore, to fill the research gap and develop a research model based on UTAUT2 and ECT theories to discover the most influential factors that affect future intentions to use tele-health systems. As for the remainder of the paper, Sec-tion 2 describes the research background of factors that influence the intention of respondents to use telehealth services. Section 3 highlights the evolution of the hy-potheses while Section 4 discusses the research method-ology. Section 5 presents the results from the data analy-sis. Section 6 highlights the discussion of data analytics while Section 7 presents the conclusions and recom-mendations drawn from the research.

\section{RELATED STUDIES}

The novel coronavirus disease 2019 (COVID-19) had spread to Malaysia via Singapore on $24^{\text {th }}$ January 2020. The pandemic has set a huge challenge to the delivery of neurosurgical services including the transfer of patients. Patients are triaged depending on their urgent needs for surgery or transferred to a neurosurgical center and man-aged accordingly. All patients are screened for the poten-tial risk of contracting COVID-19 before any surgery [2]. General surgery departments in Malaysia are part of Ma-laysia's tertiary centers that treat COVID-19 patients. The core highlights of these strategies during this pandemic are (1) surgery ward and clinic decongestions; (2) defer-ment of elective surgeries; (3) restructuring of medical personnel; (4) utilization of online applications for tele-communication; (5) operating room adjustments and patient screening; and (6) continuous learning and up-date practices in terms of COVID-19. These adaptations are important for the continuation of emergency surgery services, prevention of transmission of COVID-19 amongst healthcare workers, and optimization of the medical personnel workforce in times of a global pan-demic [3]. Patients are evaluated by a psychiatrist in the COVID-19 wards where they are hospitalized. The con-sultants wearing personal protective equipment provided for them enter the rooms of patients with COVID-19 to reduce their risks of exposure [4]. As the novel corona-virus SARS-CoV-2 (COVID-19) outbreak is highly conta-gious, there has been an urgent need to devise and iden-tify new models of delivering healthcare to avoid 'face-to-face' consultation between clinician and patient, thus reducing the risk of disease transmission [5]. In the ab-sence of high-tech communication facilities, resuming healthcare services during ongoing lockdown is highly demanding for related healthcare facilities in the country [6]. M-health may be a valuable strategy for expanding health coverage and empowering people to track their health, as well as potentially lowering medical costs [11]. Malaysia, as a developing nation with a strong technology market, should benefit from the use of $m$-health services due to its high Internet and broadband penetration rates, as well as its high smartphone penetration rate of $144.8 \%$, showing that the majority of Malaysians own multiple mobile devices [1]. Teleconsultation is an exam-ple of $\mathrm{m}$ health where patients communicate with a healthcare specialist via video chat or online platforms that provide videos of physical activities based on a physi-cal therapist's training programs. This technology can be valuable only when people start using it, given its known benefits. Consequently, end users' general attitude towards embracing telehealth services may play an important role [7]. However, most people are hesitant in using such technology. Hence, there is a need to explore to what extent the patients trust such systems [8]. There is a need to study the aspects that influence people's acceptance of teleconsultation in Malaysia.

\section{A. Expectation-Confirmation}

The Expectation Confirmation Theory (ECT), presented by Oliver in 1980, describes consumer satisfaction because of the disaffirmation of desires and aspirations. Using ECT, Oliver argued that the shift in mood and intention of the customer is caused by satisfaction [1517] Bhattacherjee subsequently proposed in 2001 to provide information systems (IS) consistency with ECT. Bhattacherjee pro-posed that the decision of IS users to continue is like the decision of customers to buy back, as both are based on initial knowledge of IS or product use. Therefore, both are closely related to customer satisfaction [18]. The more expectations people have on technology, the more de-sire they must use it. The continuous intention of using information systems for compulsory use was investigated and the value of user satisfaction was found by Sorebo and Eikebrokk [19]. IT uses were described by Rai, Lang, and Welker in 2002 as an undemanding, but not neces-sarily voluntary, systembased usage due to social pres-sure and environmental subjective norms [20]. ECT is widely used in different post-adoption contexts. It ends with the assumption that the extent of user confirmation and perceived usefulness are the main determinants of user satisfaction. Hence, confirmation and satisfaction are linked favorably. Usefulness and satisfaction also affect individuals' continuous intent to use technology [21]. In this context, the following hypothesis is proposed:

H1: Performance is positively associated with users' confir-mation of continuous use of telehealth technology.

\section{B. Actual use}

In terms of better work results (effectiveness), fast com-pletion (efficiency), and a positive attitude to a job (en-gagement), technical usefulness is the product of task success [22-24]. The expectations of technical usefulness and satisfaction [25-29] have been related to 
improved task efficiency. For example, satisfaction and prior experi-ence regulate the desire to proceed with Internet-based learning technology [30]. Furthermore, a strong relation-ship between perceived usefulness, confirmation, and satisfaction has been developed [31]. Prior experience of using technology plays a main role in usage continuation. For example, if a user perceives better organizational and technological support and ICT services, the more the e-learning program is used. The present study defined the qualities that trigger actual use and ongoing use of e-learning systems to be considerably beneficial [57]. In this context, the following hypothesis is proposed:

H2: Actual use is positively associated with users' continuous intention of telehealth technology usage.

\section{Ease of use}

Technology has to be seen as a useful tool to assist peo-ple in doing their jobs easily [32]. The ease of learning and user-intuitiveness of the system can be measured by the users revisiting the technology and not having to re-learn the tools to effectively perform a task [33-35]. If the system is easy to learn, effective, and efficient, people will be more interested to use it. Minimizing errors that may exist in the technology plays a main role to attract more people to use it [36]. For example, in e-learning education, the nature of effort expectation implies the extent of its acceptability and usage. Past studies of tech-nology adoption have shown that efforts are anticipated, both voluntary and involuntary, during the early steps of technology usage and are negligible over time for sus-tainable usage [37]. In this context, the following hy-pothesis is proposed:

H3: Ease of technology use is positively associated with users' continuous intention of telehealth technology usage.

\section{Effort expectancy}

Previous researches have shown that whenever the effort to understand and learn new technology is lesser, users tend to have more intention of using the technology. Public relations professionals, for example, have been influenced by the simplicity and self-efficacy of the me-dia [38]. For example, in inpatient management, effort expectation is also projected as a key indicator of patients' likeability of using mobile systems [23]. Effort expectancy refers to the degree to which the systems are easy or difficult to be accepted and used. Previous studies on technology acceptance have shown that during the early stages of technology adoption, effort expectancy is significant, both voluntary and involuntary, and becomes insignificant over time for sustainable use [37]. In this context, the following hypothesis is proposed:

H4: Effort expectancy is positively associated with users' continuous intention of telehealth technology usage.

\section{E. Performance}

Several studies have tested and validated the relationship between confirmation, usefulness, satis- faction, and con-tinuous intention [18], [40-42]. For example, the degree of confidence in Internet banking services has influenced the degree of perceived usefulness and satisfaction of the services [18]. Kim [18] showed that the relationship between perceived confirmation and usefulness upon goods purchased has a positive impact on the e-commerce satisfaction of consumers. The perceived amount of usefulness affects satisfaction and intention to use e-learning technology [41]. Students' performance expectancy refers to the degree to which the system allows the students to perform better in their curriculum. Preliminary studies have recognized that technology use in both voluntary and obligatory settings is strongly ex-pected to be employed by performance factors $[43,44][39]$. The expected performance has a significant impact on a system's continuous use in various studies. In this context, the following hypothesis is proposed:

H5: Expected performance is positively associated with users' continuous intention of telehealth technology usage.

\section{F. Price}

Price is described as a cognitive trade-off of the consum-ers between the perceived advantages of apps and the monetary cost of using them [45][46]. There are three types of pricing schemes in the modern app market: free, paid, and freemium. Free apps are free to download and use while paid applications must be paid for by users be-fore they can be downloaded. Freemium schemes pro-vide users with the ability to test the application for free before agreeing to buy the premium features [47]. Con-sumers demand higher quality or improved services if they pay for them [48]. In this context, the following hy-pothesis is proposed:

H6: Price is associated with users' continuous intention of telehealth technology usage.

\section{G. Technology readiness}

According to Parasuraman [49], technology readiness refers to one's propensity to embrace new technology to achieve goals in one's life at home and work. It is a multifaceted construction that has four dimensions: optimism (a positive perception of technology and a belief that it gives people greater control, flexibility, and efficiency in their lives), innovation (a tendency to become a technology pioneer), discomfort (a perceived lack of control over technology and a feeling of being overwhelmed by it), and insecurity (disruption). Optimism and innovativeness serve as the key drivers of technology readiness. They encourage people to use new technology and foster per-ceptions of safety and novelty [31]. Discomfort and inse-curity, on the other hand, are inhibitors of development readiness. They make customers hesitant to adopt new technology and create feelings of fear, confusion, and discomfort. Meanwhile, health-related information chan-nels and apps are seen as an innovative technology that can facilitate healthy behavior. Hence, the willingness of people to use applications affects their 
efficacy, as some people are technology pessimists [50]. In this context, the following hypothesis is proposed:

H7: Technology readiness is associated with users' continu-ous intention of telehealth technology usage.

\section{H. Usefulness}

The perceived service quality in the initial phase is de-scribed as the degree of an individual's expectation that the current system would improve the efficiency of a given task. Literature has shown the usefulness and im-portance of a particular technology for users' intention change [51]. As Bhattacherjee introduced ECT coupled with the technology acceptance model (TAM), it has been confirmed that perceived usefulness influences not just the implementation of IS, but also users' comfort and persistent desire to use it. Several studies have described the association between perceived usefulness, satisfac-tion, and continuous usage desire [52], [53]. Compared to the findings of earlier research, we predicted a beneficial impact of perceived usefulness on user satisfaction and continuous usage intention [54]. In this context, the fol-lowing hypothesis is proposed:

H8: Usefulness is associated with users' continuous intention of telehealth technology usage.

\section{Facilitating conditions}

In a longitudinal study of Chen [7], facilitation of condi-tions refers to the degree to which people feel that the technical and institutional facilities are available to pro-mote the use of technology. The original UTAUT has shown that facilitating conditions only substantially im-pact actual use. Further studies, including a meta-analysis of 43 studies on technology acceptance, have shown that facilitating conditions also have positive effects on behav-ioral purposes [63]. For example, previous e-learning ac-ceptability studies have demonstrated that ease-of-use conditions have a positive

Table 1. The proposed research hypotheses

\begin{tabular}{|c|c|c|}
\hline Factors & Abb* & Hypothesis \\
\hline Actual Use & ATS & $\begin{array}{l}\text { H1: Actual use positively influences continuous } \\
\text { intention of use }\end{array}$ \\
\hline Performance & PER & $\begin{array}{l}\text { H2: Performance positively influences } \\
\text { confirmation }\end{array}$ \\
\hline Ease of use & EOS & $\begin{array}{l}\text { H3: Ease of use positively influences } \\
\text { continuous intention of use }\end{array}$ \\
\hline $\begin{array}{l}\text { Effort } \\
\text { expectancy }\end{array}$ & EX & $\begin{array}{l}\text { H4: Effort expectancy positively influences } \\
\text { continuous intention }\end{array}$ \\
\hline Confirmation & COF & $\begin{array}{l}\text { H5: Confirmation positively influences user } \\
\text { satisfaction }\end{array}$ \\
\hline Price & PR & H6: Price influences continuous intention of use \\
\hline $\begin{array}{l}\text { Technology } \\
\text { readiness }\end{array}$ & TR & $\begin{array}{l}\text { H7: Technology readiness positively influences } \\
\text { continuous intention of use }\end{array}$ \\
\hline Usefulness & USF & $\begin{array}{l}\text { H8: Usefulness positively influences } \\
\text { continuous intention of use }\end{array}$ \\
\hline $\begin{array}{l}\text { Facilitating } \\
\text { conditions }\end{array}$ & FC & $\begin{array}{l}\text { H9: facilitating conditions positively influence } \\
\text { the continuous intention of use }\end{array}$ \\
\hline Satisfaction & SAT & $\begin{array}{l}\text { H10: user satisfaction positively influences } \\
\text { continuous intention of use }\end{array}$ \\
\hline
\end{tabular}

*Abb: Abbreviation effect on the intention to use [54]. The indication is that the better the students per-ceive the organizational and technical support, and ICT infrastructure, the more the e-learning system is used. The current study has hypothesized the facilitation of conditions that makes people keener to use telehealth. In this context, the following hypothesis is proposed:

H9: Facilitating conditions are associated with users' contin-uous intention of telehealth technology usage.

\section{J. Satisfaction}

Consumer satisfaction can be defined as consumer per-ception of the extent to which consumer requirements have been met [55]. Keiningham, Perkins-Munn, and Ev-ans confirmed the definition of satisfaction where con-sumer satisfaction has an impact on consumer behavior. In addition, high consumer satisfaction leads to higher consumer loyalty and buying intentions [56]. For exam-ple, market research has shown that the main reason for a consumer's decision to re-purchase or re-use a product is their level of satisfaction $[17],[57,58]$. Bhattacherjee had empirically shown that level of satisfaction is a critical factor in decision-making [18]. In this context, the follow-ing hypothesis is proposed:

H10: Satisfaction is associated with users' continuous inten-tion of telehealth technology usage.

\section{METHODS AND MEASURES}

This study aims to examine and investigate the causes that shape and influence the intention to use telehealth among Malaysians. Figure 1 represents the research model of this study. Telehealth intention was considered as a dependent variable. Students in Malaysian universi-ties were the targeted population for this study. To en-sure the validity of all measures, individual constructs of the determinants were adapted from previous research, provided in this paper.

Table 2. Demographics information of the participants

\begin{tabular}{|c|c|c|c|c|c|}
\hline Gender & $\mathbf{N}$ & $\%$ & & & \\
\hline Female & 75 & $\% 49$ & & & \\
\hline Male & 79 & $\% 51$ & & & \\
\hline Study level & $\mathbf{N}$ & $\%$ & & & \\
\hline Undergraduate & 129 & $\% 84$ & & & \\
\hline Postgraduate: & 25 & $\% 16$ & & & \\
\hline \multicolumn{6}{|c|}{ Online Health care services familiarity } \\
\hline \multirow{3}{*}{$\begin{array}{l}\text { I like to use } \\
\text { websites to } \\
\text { get health care } \\
\text { services }\end{array}$} & $\begin{array}{l}\text { Strongly } \\
\text { disagree }\end{array}$ & Disagree & Neutral & Agree & $\begin{array}{c}\text { Strongly } \\
\text { Agree }\end{array}$ \\
\hline & 5 & 7 & 40 & 50 & 52 \\
\hline & $3.2 \%$ & $4.5 \%$ & $25.9 \%$ & $32.4 \%$ & $33.7 \%$ \\
\hline Living & $\mathbf{N}$ & $\%$ & & & \\
\hline Urban & 123 & $79.9 \%$ & & & \\
\hline Rural & 31 & $20.1 \%$ & & & \\
\hline \multirow[t]{2}{*}{ Age } & $\mathbf{N}$ & $\%$ & & & \\
\hline & $\begin{array}{c}\text { Between } \\
21 \text { and } 30 \\
154\end{array}$ & $100 \%$ & & & \\
\hline
\end{tabular}


To test the multiple hypotheses, this study collected online survey data of full-time students from the University of Kuala Lumpur, Malaysia. The survey asked students to examine their acceptance of telehealth services. Two hundred and eight responses were initially received. Out of the 208 responses collected, 54 (i.e. incomplete, outlier) responses were dropped while 54 respondents were chosen. Table 1 shows the demographics information of the respondents. Eight responses were initially received.

The construction and research model in Figure 1 was developed based on a comprehensive literature review as described above. The independent constructs of the theoretical model consisted of Actual Use, Confirmation, Ease of Use, Effort Ex-pectancy, Performance, Price, Technology Readiness, Usefulness, Facilitating Conditions, and Satisfaction. Intent to Use was stated as the dependent variable. These constructs were derived from previous studies, with minor modifications in the lan-guage of the items used to capture the data. A 5-point Likert scale was used to capture the answers for each item, with 1 being strongly agreed and 5 as Strongly Disagree. Several demographic items that use various measurement scales, were also included in the questionnaire. We used partial least squares (PLS) for data analysis and research model testing. PLS path modeling is a variance-based structural equation modeling (SEM) technology that is widely implemented in business and social sciences. Its ability to simulate composites and factors makes it an effective computational method for new technology studies [59]. The advantages of SEM relative to firstgeneration statistical techniques include more robust assumptions where multicollinearity is partly enabled and less error of calculation is used with confirmatory factor analysis (CFA) [60]. We evaluated the model using the Smart PLS 3.0 bootstrapping methodology $[60,61]$.

\section{RESULTS}

The details shown in Table 2 indicate that 51\% are male interviewees while $49 \%$ are female. Most participants (75\%) are Bachelor's degree holders. Appendix A shows the questions.

\section{A. Measurement Model Assessment}

To measure the internal consistency of the hypothesized model, Cronbach's Alpha along with composite reliability and av-erage variance extracted (AVE) was used. Table 2 shows that the composite reliability values are between $93.3 \%$ and $78.3 \%$ which exceed the recommended threshold of 70\% [62]. However, Cronbach's Alpha values are below, between $87.5 \%$ and $60.3 \%$. Some items are below 70\%, consisting of EX, EOS, SAT, TR, and Perceived USF. A low Cronbach's Alpha indicates a result of test length and dimensionality [62]. Therefore, all the indicators were considered reliable. Furthermore, the average variance extracted (AVE) method was used to measure the convergent validity of the selected items between 49.5 and 82.2. Table 2 shows that the AVE values of all the constructs are more than 0.5 except the TR construct, which assumed ade-quate convergent validity [62].
Table 3. Measurement Model Assessment

\begin{tabular}{|c|c|c|c|c|c|}
\hline \multicolumn{2}{|c|}{ Constructs } & \multirow{2}{*}{$\begin{array}{c}\text { Loading } \\
0.919\end{array}$} & \multirow{3}{*}{$\begin{array}{l}\text { AVE* } \\
0.808\end{array}$} & \multirow{3}{*}{$\begin{array}{l}\text { CR }^{* *} \\
0.894\end{array}$} & \multirow{3}{*}{$\begin{array}{l}\text { Alpha } \\
0.765\end{array}$} \\
\hline & ATS 1 & & & & \\
\hline & ATS 2 & 0.879 & & & \\
\hline \multirow{6}{*}{ COF } & COF 1 & 0.702 & \multirow[t]{6}{*}{0.616} & \multirow[t]{6}{*}{0.906} & \multirow[t]{6}{*}{0.875} \\
\hline & COF 2 & 0.723 & & & \\
\hline & COF 3 & 0.814 & & & \\
\hline & COF 4 & 0.791 & & & \\
\hline & COF 5 & 0.857 & & & \\
\hline & COF 6 & 0.812 & & & \\
\hline \multirow{3}{*}{ EX } & EX 1 & 0.912 & \multirow[t]{3}{*}{0.822} & \multirow[t]{3}{*}{0.933} & \multirow[t]{3}{*}{0.616} \\
\hline & EX 2 & 0.923 & & & \\
\hline & EX 3 & 0.884 & & & \\
\hline \multirow{4}{*}{$\mathrm{FC}$} & FC 1 & 0.814 & \multirow[t]{4}{*}{0.581} & \multirow[t]{4}{*}{0.847} & \multirow[t]{4}{*}{0.762} \\
\hline & FC 2 & 0.787 & & & \\
\hline & $\mathrm{FC} 3$ & 0.782 & & & \\
\hline & FC 4 & 0.658 & & & \\
\hline \multirow{3}{*}{ EoS } & EoS 1 & 0.297 & \multirow[t]{3}{*}{0.578} & \multirow[t]{3}{*}{0.778} & \multirow[t]{3}{*}{0.616} \\
\hline & EoS 2 & 0.931 & & & \\
\hline & EoS 3 & 0.882 & & & \\
\hline \multirow{3}{*}{ PER } & PER 1 & 0.858 & \multirow[t]{3}{*}{0.757} & \multirow[t]{3}{*}{0.903} & \multirow[t]{3}{*}{0.84} \\
\hline & PER 2 & 0.85 & & & \\
\hline & PER 3 & 0.901 & & & \\
\hline & tructs & Loading & AVE* & $\mathbf{C R}^{* *}$ & Alpha \\
\hline & PR 1 & 0.926 & 0.797 & 0.887 & 0.75 \\
\hline & PR 1 & 0.858 & & & \\
\hline & SAT 1 & 0.903 & 0.575 & 0.783 & 0.603 \\
\hline SAT & SAT 2 & 0.885 & & & \\
\hline & SAT 3 & 0.356 & & & \\
\hline & TR 1 & 0.648 & 0.495 & 0.795 & 0.657 \\
\hline & TR 2 & 0.712 & & & \\
\hline TR & TR 3 & 0.815 & & & \\
\hline & TR 4 & 0.623 & & & \\
\hline & CTU 1 & 0.641 & 0.623 & 0.92 & 0.898 \\
\hline & CTU 2 & 0.809 & & & \\
\hline & CTU 3 & 0.824 & & & \\
\hline CTU & CTU 4 & 0.782 & & & \\
\hline & CTU 5 & 0.783 & & & \\
\hline & CTU 6 & 0.861 & & & \\
\hline & CTU 7 & 0.808 & & & \\
\hline & USF 1 & 0.751 & 0.612 & 0.825 & 0.683 \\
\hline USF & USF 2 & 0.848 & & & \\
\hline & USF 3 & 0.744 & & & \\
\hline
\end{tabular}

*AVE: Average variance extracted **CR: Composite Reliability 
Table 4. Correlation analysis

\begin{tabular}{|c|c|c|c|c|c|c|c|c|c|c|c|}
\hline & ATS & COF & CTU & Eos & EX & PER & PR & TR & USF & FC & SAT \\
\hline ATS & 0.899 & & & & & & & & & & \\
\hline COF & 0.485 & 0.785 & & & & & & & & & \\
\hline CTU & 0.477 & 0.809 & 0.79 & & & & & & & & \\
\hline Eos & 0.35 & 0.588 & 0.499 & 0.76 & & & & & & & \\
\hline EX & 0.537 & 0.73 & 0.759 & 0.533 & 0.907 & & & & & & \\
\hline PER & 0.453 & 0.835 & 0.778 & 0.569 & 0.647 & 0.87 & & & & & \\
\hline PR & 0.287 & 0.566 & 0.636 & 0.336 & 0.519 & 0.496 & 0.892 & & & & \\
\hline TR & 0.265 & 0.461 & 0.439 & 0.419 & 0.441 & 0.357 & 0.349 & 0.703 & & & \\
\hline USF & 0.425 & 0.753 & 0.764 & 0.494 & 0.674 & 0.668 & 0.578 & 0.51 & 0.782 & & \\
\hline FC & 0.362 & 0.608 & 0.639 & 0.482 & 0.642 & 0.478 & 0.553 & 0.541 & 0.683 & 0.762 & \\
\hline SAT & 0.475 & 0.75 & 0.761 & 0.635 & 0.711 & 0.697 & 0.623 & 0.424 & 0.692 & 0.609 & 0.758 \\
\hline
\end{tabular}

Table 5. Hypothesis testing

\begin{tabular}{|c|c|c|c|c|c|c|}
\hline & $\begin{array}{l}\text { Original Sample } \\
(0)(\beta)\end{array}$ & $\begin{array}{c}\text { Sample Mean } \\
\text { (M) }\end{array}$ & $\begin{array}{c}\text { Standard } \\
\text { Deviation } \\
\text { (STDEV) }\end{array}$ & $\begin{array}{l}\text { T Statistics }(\mid \mathbf{O} / \\
\text { STDEV } \mid)\end{array}$ & P Values & Conclusion \\
\hline H1: ATS ->CTU & 0.04 & 0.055 & 0.051 & 0.787 & 0.432 & Not supported \\
\hline $\mathrm{H} 2$ : COF $->$ PER & 0.835 & 0.838 & 0.025 & 32.899 & 0 & supports \\
\hline H3: EOS ->CTU & -0.03 & -0.037 & 0.082 & 0.36 & 0.719 & Not supports \\
\hline H4: EX ->CTU & 0.291 & 0.279 & 0.081 & 3.588 & 0 & supports \\
\hline H5: PER -> SAT & 0.697 & 0.697 & 0.056 & 12.339 & 0 & supports \\
\hline H6: PR->CTU & 0.149 & 0.156 & 0.054 & 2.75 & 0.007 & supports \\
\hline H7:TR ->CTU & -0.007 & -0.009 & 0.062 & 0.111 & 0.912 & Not supported \\
\hline H8: USF ->CTU & 0.3 & 0.31 & 0.08 & 3.744 & 0 & supports \\
\hline H9: FC ->CTU & 0.02 & 0.034 & 0.102 & 0.2 & 0.842 & Not supported \\
\hline H10: SAT ->CTU & 0.244 & 0.228 & 0.088 & 2.782 & 0.006 & supports \\
\hline
\end{tabular}

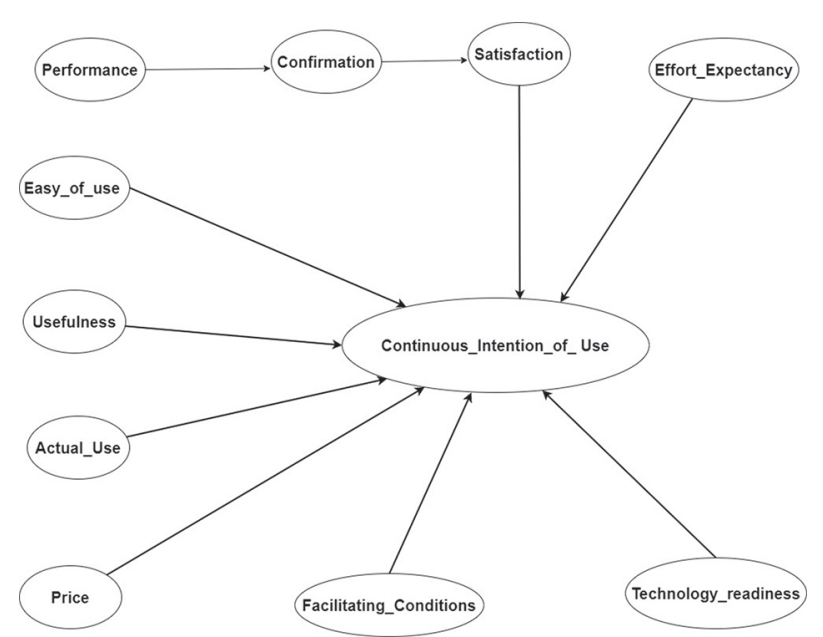

Fig. 1. Conceptual Research Model

\section{B. DISCRIMINANT VALIDITY}

This research calculated the discriminant convergent va-lidity of the contracts by comparing the square root of AVE for each construct with its cross-correlation with oth-er constructs. The results showed that the square root of AVE was found to be higher than the off-diagonal ele-ments in the corresponding rows and columns which support the discriminant criteria set for all contracts. Table 3 summarizes the results. The accepted convergent validity of each construct must exceed the correlation it exhibits with other constructs [8]. In addition, the members in the matching columns and correlation matrix rows must be lower than the diagonal element [8]. Table 3 summarizes the data that con-firm convergent validity of all contracts which are be-tween $89.9 \%$ and $70.3 \%$, indicating a minimum of 0.50 of AVE 
exists for all constructs. In addition, the entire loadings were highly significant (t-statistics $>(3.419), \mathrm{p}<(0.001)$ ) based on the output of SmartPLS, which demonstrated that the indicators represent noticeably different latent construction.

\section{Limitations}

One drawback of this study is that the sample used did not include certain classes of individuals, such as school students who are strong consumers of video games for example, and academically challenged people who are more vulnerable to overuse of digital games. Future work is expected to extend the effects of this study to a specif-ic population, such as school pupils and uneducated peo-ple.

\section{CONCLUSION}

Public confidence in telehealth services is a highly under-researched field. A major antecedent of this technology adoption is to investigate decisions on the use of tele-health services. Now that telehealth services are more popular and large quantities of personal data are being collected, the public trust in telehealth services will be-come a more important feature. This research investigat-ed the drivers and obstacles that affect the willingness of people to utilize telehealth facilities. The findings pointed out that confirmation, performance, effort expectancy, usefulness, and satisfaction were the main drivers influ-encing the acceptance of telehealth ser-vices. Furthermore, actual use, ease of use, technology readiness, and facilitating conditions did not impact participants' confidence in the use of telehealth ser-vices. Despite the substantial influences of the constructs, educating workers and the public on how to use this technology by conducting special training programs at health care institutions is suggested to familiarize them with the technology. There is also a need to upgrade the current healthcare systems and make them compatible with telehealth technology requirements. The findings of this study contributed to the existing body of knowledge of adopting and implementing new healthcare systems such as telehealth.

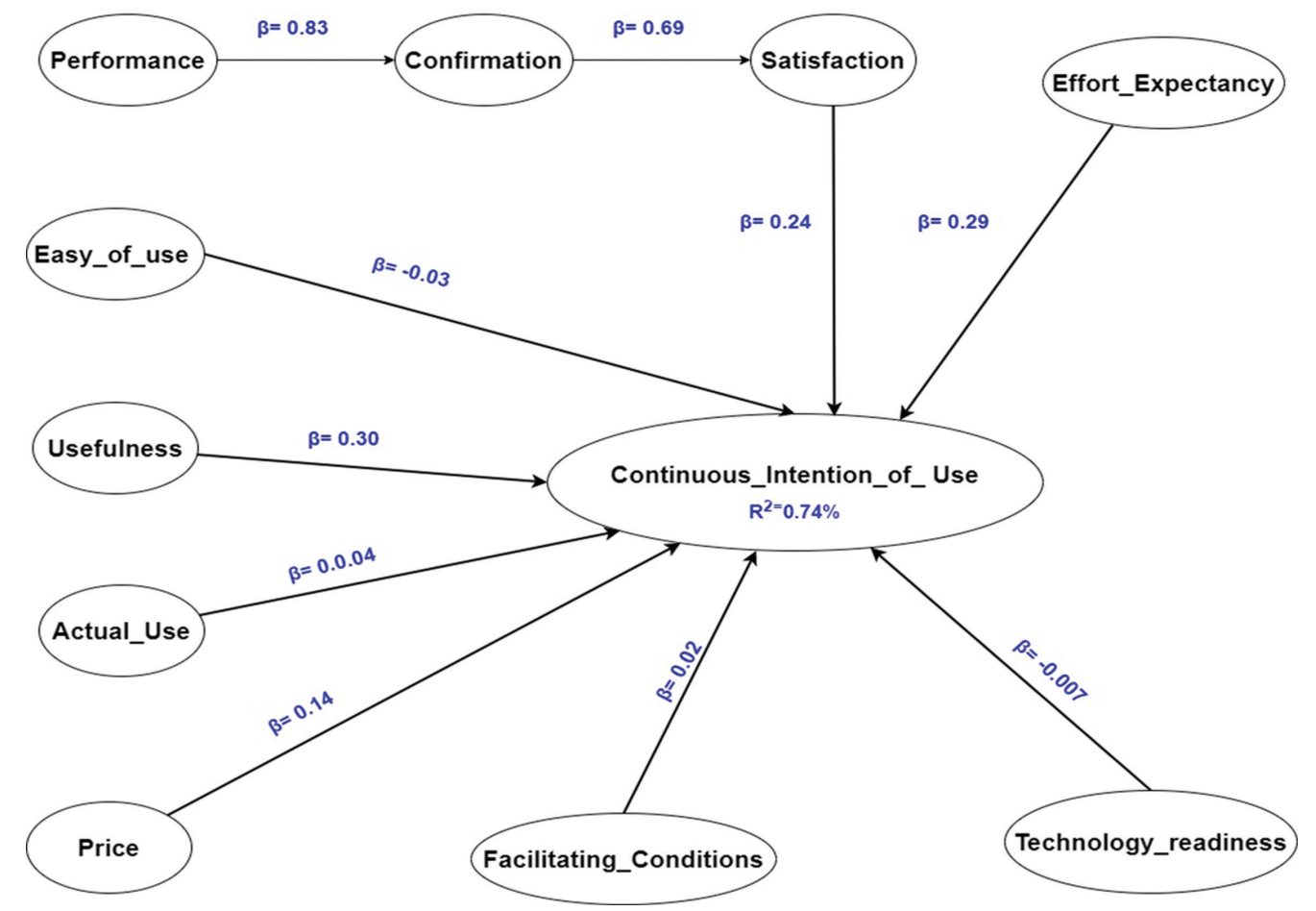

Fig. 2. Research mode

\section{REFERENCES}

[1] P. Tasca, T. Aste, L. Pelizzon, N. Perony, "Banking Beyond Banks and Money: A Guide to Banking Services in the Twenty-First Century", Springer, 2016.

[2] E. M. Al-Mukhaini, W. S. Al-Qayoudhi, A. H. Al-Badi, "Adoption of social networking in education: $A$ study of the use of social networks by higher education students in Oman", International Journal of Educational Research, Vol. 10, No. 2, pp. 143-154, 2014.
[3] S. Kosterink, "The added value of telemedicine services for physical rehabilitation", Research UT, 2014, PhD Thesis.

[4] M. J. Rho, I. young Choi, J. Lee, "Predictive factors of telemedicine service acceptance, behavioral intention of physicians", International Journal of Medical Informatics, Vol. 83, No. 8, pp. 559-571, 2014.

[5] P. Esmaeilzadeh, M. Sambasivan, N. Kumar, "The challenges, issues regarding e-health, health in- 
formation technology trends in the healthcare sector", Proceedings of the International Conference on E-business Technology, Strategy, Ottawa, Canada, 29-30 September 2010, pp. 23-37.

[6] Z. Jin, Y. Chen, "Telemedicine in the cloud era: Prospects, challenges", IEEE Pervasive Computing, Vol. 14, No. 1, 2015, pp. 54-61.

[7] S. A. Kamal, M. Shafiq, P. Kakria, "Investigating acceptance of telemedicine services through an extended technology acceptance model (TAM)", Technology in Society, Vol. 60, 2020, p. 101212.

[8] L. van Velsen, M. Tabak, H. Hermens, "Measuring patient trust in telemedicine services: Development of a survey instrument, its validation for an anticoagulation web-service", International Journal of Medical Informatics, Vol. 97, 2017, pp. 52-58.

[9] D. D. Luxton, R. A. McCann, N. E. Bush, M. C. Mishkind, G. M. Reger, "MHealth for mental health: Integrating smartphone technology in behavioral healthcare", Professional Psychology: Research and Practice, Vol. 42, No. 6, 2011, pp. 505-512.

[10] E. Årsand et al., "Mobile health applications to assist patients with diabetes: lessons learned, design implications", Journal of Diabetes Science and Technology, Vol. 6, No. 5, 2012, pp. 1197-1206.

[11] M. C. Carter, V. J. Burley, C. Nykjaer, J. E. Cade, "Adherence to a smartphone application for weight loss compared to website, paper diary: pilot randomized controlled trial", Journal of Medical Internet Research, Vol. 15, No. 4, 2013, p. e32.

[12] J. L. Bender, R. Y. K. Yue, M. J. To, L. Deacken, A. R. Jadad, "A lot of action, but not in the right direction: Systematic review, content analysis of smartphone applications for the prevention, detection, management of cancer", Journal of Medical Internet Research, Vol. 15, No. 12, 2013, p. e287.

[13] J. Cho, M. M. Quinlan, D. Park, G.-Y. Noh, “Determinants of adoption of smartphone health apps among college students", American Journal of Health Behavior, Vol. 38, No. 6, 2014, pp. 860-870.

[14] J. Cho, H. E. Lee, S. J. Kim, D. Park, "Effects of body image on college students' attitudes toward diet/ fitness apps on smartphones", Cyberpsychology,
Cyberpsychology, Behavior, and Social Networking, Vol. 18, No. 1, 2015, pp. 41-45.

[15] R. Gulati, “Does Familiarity Breed Trust? The Implications of Repeated Ties for Contractual Choice in Alliances", Academy of Management Journal, Vol. 38, No. 1, 1995, pp. 85-112.

[16] R. L. Oliver, "A Cognitive Model of the Antecedents, Consequences of Satisfaction Decisions", J. Mark. Res., Vol. 17, No. 4, 1980, pp. 460-469.

[17] E. W. Anderson, M. W. Sullivan, "The Antecedents, Consequences of Customer Satisfaction for Firms", Marketing Science, Vol. 12, No. 2, 1993, pp. 125143.

[18] A. Bhattacherjee, "Understanding Information Systems Continuance: An Expectation-Confirmation Model", MIS Quarterly, Vol. 25, No. 3, 2001, pp. $351-370$

[19] Ø. Sørebø, T. R. Eikebrokk, "Explaining IS continuance in environments where usage is mandatory", Computers in Human Behavior, Vol. 24, No. 5, pp. 2357-2371, 2008.

[20] A. Rai, S. S. Lang, R. B. Welker, "Assessing the validity of IS success models: An empirical test, theoretical analysis", Information Systems Research., Vol. 13 , No. 1, 2002, pp. 50-69.

[21] S. H. Lim, D. J. Kim, Y. Hur, K. Park, "An empirical study of the impacts of perceived security, knowledge on continuous intention to use mobile fintech payment services", International Journal of Human-Computer Interaction, Vol. 35, No. 10, 2019, pp. 886-898.

[22] R. P. McDonald, M.-H. R. Ho, "Principles, practice in reporting structural equation analyses.", Psychological Methods, Vol. 7, No. 1, 2002, p. 64.

[23] J. Baldwin, "The fire next time", Vintage, 2013.

[24] A. Sonderegger, G. Zbinden, A. Uebelbacher, J. Sauer, "The influence of product aesthetics, usability over the course of time: a longitudinal field experiment", Ergonomics, Vol. 55, No. 7, 2012, pp. $713-730$

[25] D. R. Compeau, C. A. Higgins, "Computer self-efficacy: Development of a measure, initial test", MIS Quarterly, 1995, pp. 189-211. 
[26] D. Green, J. M. Pearson, “Development of a web site usability instrument based on ISO 9241-11", Journal of Computing and Information Science in Engineering., Vol. 47, No. 1, 2006, pp. 66-72.

[27] D. T. Green, J. M. Pearson, "Integrating website usability with the electronic commerce acceptance model", Behaviour \& Information Technology, Vol. 30, No. 2, 2011, pp. 181-199.

[28] S. Toleva-Stoimenova, D. Christozov, "Informing via Websites: Comparative Assessment of University Websites", in Proceedings of the Informing Science, Information Technology Education Conference, 2013 , pp. 525-537.

[29] R. K.-J. Yeh, J. T. C. Teng, “Extended conceptualisation of perceived usefulness: empirical test in the context of information system use continuance", Behaviour \& Information Technology, Vol. 31, No. 5, 2012, pp. 525-540.

[30] M. Limayem, C. M. K. Cheung, "Understanding information systems continuance: The case of Internet-based learning technologies", Information and Management, Vol. 45, No. 4, 2008, pp. 227-232.

[31] J. Wu, R. J. Tsai, C. C. Chen, Y. Wu, "An integrative model to predict the continuance use of electronic learning systems: hints for teaching", International Journal on E-Learning, Vol. 5, No. 2, 2006.

[32] L. Baker-Eveleth, R. W. Stone, "Usability, expectation, confirmation, continuance intentions to use electronic textbooks", Behaviour \& Information Technology, Vol. 34, No. 10, 2015, pp. 992-1004.

[33] S. M. Z. Ahmed, "A comparison of usability techniques for evaluating information retrieval system interfaces", Performance Measurement and Metrics, 2008.

[34] R. P. Bringula, "Influence of faculty-and web portal design-related factors on web portal usability: A hierarchical regression analysis", Computers \& Education, Vol. 68, 2013, pp. 187-198.

[35] U. Konradt, H. Wandke, B. Balazs, T. Christophersen, "Usability in online shops: scale construction, validation, the influence on the buyers' intention, decision", Behaviour \& Information Technology, Vol. 22, No. 3, 2003, pp. 165-174.
[36] A. Chevalier, N. Fouquereau, J. Vanderdonckt, "The influence of a knowledge-based system on designers' cognitive activities: a study involving professional web designers", Behaviour \& Information Technology, Vol. 28, No. 1, 2009, pp. 45-62.

[37] V. Venkatesh, F. D. Davis, "A theoretical extension of the technology acceptance model: Four longitudinal field studies", Manage. Sci., Vol. 46, No. 2, 2000, pp. 186-204.

[38] L. Curtis et al., "Adoption of social media for public relations by nonprofit organizations", Public Relations Review, Vol. 36, No. 1, 2010, pp. 90-92.

[39] V. Venkatesh, M. G. Morris, G. B. Davis, F. D. Davis, "User acceptance of information technology: Toward a unified view", MIS Quarterly, 2003, pp. 425-478.

[40] J.-H. Lee, "A literature review on security for internet of things in Korea based on loT SPND-Se ecosystem model", Journal of Security Engineering, Vol. 12, No. 4, 2015, pp. 397-414.

[41] M.-C. Lee, "Explaining, predicting users' continuance intention toward e-learning: An extension of the expectation-confirmation model", Computers \& Education, Vol. 54, No. 2, 2010, pp. 506-516.

[42] S. H. Lim, N. J. Cho, J. H. Whang, "Role of familiarity, perceived behavioral control in adoption, continual use of RFID services", Korea Logistic Review, Vol. 22, No. 3, 2012, pp. 5-25.

[43] Y. K. Dwivedi, N. P. Rana, H. Chen, M. D. Williams, "A Meta-analysis of the Unified Theory of Acceptance, Use of Technology (UTAUT)", Proceedings of the IFIP international working conference on governance, sustainability in information systemsmanaging the transfer, diffusion of it, Hamburg, Germany, 22-24 September2011, pp. 155-170.

[44] B. ŠUmak, M. HeričKo, M. PušNik, "A meta-analysis of e-learning technology acceptance: The role of user types, e-learning technology types", Computers in Human Behavior, Vol. 27, No. 6, 2011, pp. 2067-2077.

[45] V. Venkatesh, J. Y. L. Thong, X. Xu, “Consumer acceptance, use of information technology: extending the unified theory of acceptance, use of technology", MIS Quarterly, 2012, pp. 157-178. 
[46] W. B. Dodds, K. B. Monroe, D. Grewal, "Effects of price, brand, store information on buyers' product evaluations", Journal of Marketing Research, Vol. 28, No. 3, 1991, pp. 307-319.

[47] J. H. West, P. C. Hall, C. L. Hanson, M. D. Barnes, C. Giraud-Carrier, J. Barrett, "There's an app for that: Content analysis of paid health, fitness apps", Journal of Medical Internet Research, Vol. 14, No. 3, 2012, p. e72.

[48] V. A. Zeithaml, "Consumer perceptions of price, quality, value: a means-end model, synthesis of evidence", Journal of Marketing, Vol. 52, No. 3, 1988, pp. 2-22.

[49] A. Parasuraman, "Technology Readiness Index (TRI) a multiple-item scale to measure readiness to embrace new technologies", J. Serv. Res., Vol. 2, No. 4, 2000, pp. 307-320.

[50] M. L. Meuter, A. L. Ostrom, R. I. Roundtree, M. J. Bitner, "Self-service technologies: understanding customer satisfaction with technology-based service encounters", Journal of Marketing, Vol. 64, No. 3, 2000, pp. 50-64.

[51] P. C. Lai, "The literature review of technology adoption models, theories for the novelty technology", JISTEM-Journal Inf. Syst. Technol. Manag., Vol. 14, No. 1, 2017, pp. 21-38.

[52] R. Zhou, X. Wang, Y. Shi, R. Zhang, L. Zhang, H. Guo, "Measuring e-service quality, its importance to customer satisfaction, loyalty: an empirical study in a telecom setting", Electronic Commerce Research, Vol. 19, No. 3, 2019, pp. 477-499.

[53] C.-H. Hsiao, "The effects of post-adoption beliefs on the expectation-confirmation model in an electronics retail setting", Total Quality Management and Business Excellence, Vol. 29, No. 7-8, 2018, pp. 866-880.

[54] M. Park, J. Jun, H. Park, “Understanding Mobile Payment Service Continuous Use Intention: An Expectation-Confirmation Model, Inertia", Quality Innovation Prosperity, Vol. 21, No. 3, 2017, pp. 78-94.
[55] M. Horváth, A. Michalkova, "Monitoring Customer Satisfaction in Service Industry: A Cluster Analysis Approach", Quality Innovation Prosperity, Vol. 16, No. 1, 2012, pp. 49-54.

[56] T. L. Keiningham, T. Perkins-Munn, H. Evans, "The impact of customer satisfaction on share-of-wallet in a business-to-business environment", Journal of Service Research, Vol. 6, No. 1, 2003, pp. 37-50.

[57] P. Kotler, G. Armstrong, "Principles of marketing. Pearson education", 2010.

[58] T. Fernandes, R. Pedroso, "The effect of self-checkout quality on customer satisfaction, repatronage in a retail context", Service Business, Vol. 11, No. 1, pp. 69-92, 2017.

[59] J. Henseler, "Bridging design, behavioral research with variance-based structural equation modeling", Journal of Advertising, Vol. 46, No. 1, 2017, pp. 178-192.

[60] I. B. Hong, H. S. Cha, "The mediating role of consumer trust in an online merchant in predicting purchase intention", International Journal of Information Management, Vol. 33, No. 6, 2013, pp. 927-939.

[61] M. Wetzels, G. Odekerken-Schröder, C. Van Oppen, "Using PLS path modeling for assessing hierarchical construct models: Guidelines, empirical illustration", MIS Quarterly, 2009, pp. 177-195.

[62] C. Fornell, D. F. Larcker, "Evaluating structural equation models with unobservable variables, measurement error", Journal of Marketing Research, Vol. 18, No. 1, 1981, pp. 39-50.

[63] Y. K. Dwivedi, N. P. Rana, H. Chen, M. D. Williams, "A Meta-analysis of the Unified Theory of Ac-ceptance and Use of Technology (UTAUT)", Pro-ceedings of the IFIP international working con-ference on governance and sustainability in in-formation systems-managing the transfer and dif-fusion of it, Hamburg, Germany, 22-24 Septem-ber 2011, pp. 155-170. 


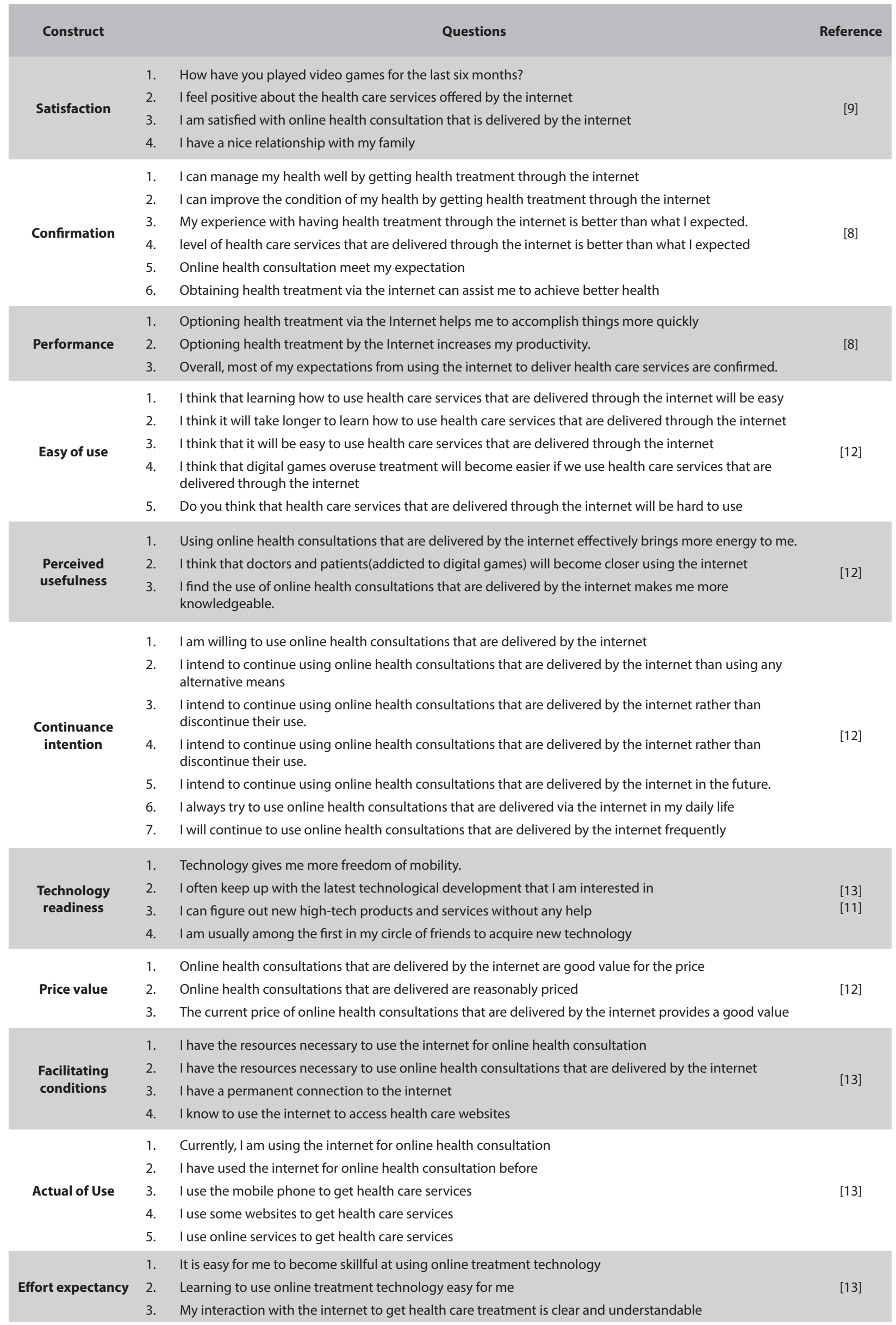

